\title{
A Promising Approach in the World: Tensile Structures Roofing
}

\author{
Talha Ekmekyapar, Alaa Tareq Al-Shareef,, Derya Bakbak \\ Department of Civil Engineering University of Gaziantep, Gaziantep, Turkey \\ Phone: +90 5355451194; E-mail: aalsharif80@yahoo.com.tr
}

\begin{abstract}
Civil engineering roof systems for outdoor environments find use in bazaars, car park areas, outdoor sport facilities and places built to protect people or their goods from environmental effects such as sun and heavy rain. Therefore, such roofing systems have great amount of application and each country spends huge volumes of materials to build these roof systems to improve life quality of people in cities. Thus, it is evident that further research on these civil engineering structures has the potential to decrease the cost of these roof systems and build more efficient ones. Generally these roof systems are manufactured employing structural steel material. As is well known, steel has promising mechanical properties such as high strength and high stiffness which can be exploited in structures that expected to receive very high magnitude of loadings, such as earthquake resistant buildings. However, there also exist some disadvantages of completely using steel in these roof systems. For instance, due to unit weight of material the roofs manufactured using steel are very heavy. So, construction process requires significant labour and time. Also steel construction is an expensive process considering measure of covered area for outdoor roof systems. Moreover, these kinds of roofs manufactured using completely steel are not flexible in use, that is to say, when it is unnecessary for some period of time it is not possible to remove the roof covering and re-cover it when it is necessary again. This paper investigates a novel concept in the world called as "tensile structures" used to cover wide outdoor areas. This concept actually combines civil engineering designs and some architectural aspects. Instead of using materials with high stiffness, tensile structures adapt membrane materials to cover wide areas. Cable elements accompany those membranes to transmit the internal forces and stresses to structural columns or ground. Although membrane materials have lower strengths compared to steel, these structures offer flexibility in use, light coverings, lower costs and faster construction time. Since these structures are built utilizing membrane materials and cables which support tension forces only, conventional stress office methods are not capable of handling their analyses and designs. Consequently, specific computational methods must be used to perform such designs. In this paper special commercial software is used to investigate behaviour of tensile structures. Three different configurations are employed to cover a wide area. Structural analysis procedures of those configurations are undertaken and stress distributions in membranes are investigated. Discussions pertaining to motivation behind these structures, load carrying capabilities and working principles are provided. Outcomes of this study illustrate that these tensile structures have the potential to replace some applications of steel roofs to lead lighter, flexible, low cost and more aesthetic structures for outdoor environments.
\end{abstract}

Index Terms- Tensile structures, outdoor roofing, structural mechanics

\section{INTRODUCTION}

$\mathrm{T}$ Roof systems designed by used tensile structures to enclosed modern structures such stadiums and shopping centres to span large areas cover. Afford the architect the opportunity for imaginative creation and the same time network of slender cables provide the strength necessary to support the tremendous loads involved. Space activities provide further applications for the tensile structure concept since weight is a principal factor in determining feasibility [1]. Most often, tensile structures are used for a dramatic effect over performance and outdoor exhibition areas, music stages, parking areas, entrance driveways, walkways, theatres, airport, domes, stadia. Designed as demountable canopies or permanent, they act as a foil for lighting and the projection of images, and can also be used for protecting audiences from the elements. The architecture in second half of twentieth century. After the war, young architects, engineers, and entrepreneurs had been looking for new integrated part of it instead. It was of prime importance, with the minimal material and energy, to rebuild the destroyed cities in a more effective and beautiful way at that time [2]. Nowadays, it is recognized for the first time that conservation and care of nature and a liveable, sustainable environment should be selection and design of architectural forms. It is essential to conserve and protect the fundamental home of our mankind [3]. Tensile structure is made of tensile materials, cables and/or membranes, in which there is neither bending, compression nor torsion but only tension forces/stresses exist. It is usually used as a large-span structure because of the light-weight characteristics of the structural materials and absence of elements that may have buckle. Through tension structures come in varying size, scale, shape and form, all of them consists of the same basic elements [4]:

- A lightweight and flexible fabric members, tensioned for stability and usually used as a roofing element,

- Flexible linear elements such as ties or cables, which are commonly used at boundaries or edges, and

- Rigid supporting members such as masts, frames, ring, arches and edge beams, which usually transfer 
loads in compression. These rigid supports are typically made from traditional building materials such as steel, concrete and timber.

Through there are variety of ways to categorize tensile membrane structure. Lewis [5] divided them into three main groups:

\section{Boundary tensioned membranes}

Boundary tensioned membranes are stressed by stretching the surface to meet the boundary made of flexible, tension cables, or a rigid frame/beam. The boundary elements are an important part of the tension structure as they determine the shape and nature of not just the boundary but the surface as whole. The former has zero excess pressure between the outer and inner surface $[5,6]$. Under imposed loads, such as wind and snow the stress in the surface can increase and fold design of tension membranes is aimed at keeping the initial priestess at approximately $1 / 20$ of the breaking strength of the cloth [5].

\section{Pneumatic or air supported structures}

Pneumatic structures or 'air houses' are thin membranes stressed by internal air pressure generated by fans. Their shape is very strongly affected by the difference between the external and internal pressures, which change continually, as a result of temperature variations, wind and snow load conditions. Air houses are designed to maintain an internal pressure between $0.2 \mathrm{kN} / \mathrm{m} 2$ and $0.55 \mathrm{kN} / \mathrm{m} 2$ [5].

\section{Cable-nets and cable-beams}

Cable nets can be stressed directly using rigid supports such as compression ring beams, or flexible edge cables with supporting mast and tie backs. They can take the form of suspended structure stabilized by means of a heavy roof cladding, or can be encased in concrete. The opportunity for creating new structural form is immense. If a priestesses cable net constitutes a part of a concrete shell, it is no longer a lightweight tension structure and the advantage of flexible is lost. However, because of their apparent visual lightness, the shapes of cable net structures are copied in to rigid forms, as was the case with concrete 'tents' constructed in the Middle East in1991 [5]. The main difference between cable nets and fabric structures, from the structural view point, is that fabric structures are capable of sustaining membrane shear forces whereas cable nets are not, due to the deformability of the surface.

\section{The Advantages of Tensile Membrane Structures}

The growing interest in tensile structures can be attributed to following advantages: Provided appropriate and well designed structural forms are utilized these structure can become very attractive architectural landmarks.

Many fabric architectural structures are designed so that the fabric can be removed if there is danger of a hurricane. The helps prevent damage to a structure in a way that is not possible with roofed building structures. It also helps prevent damage to surrounding property from flying shingles or metal roofs.

Adapts its own, unique shape. Because of their uniqueness and originality, fabric structures can attract extra attention to a business. Adding attractive signage and logos to help advertise businesses.

- They are light weight and can be transported at relatively low cost.

- These structures can be used to cover large areas at very competitive costs per unit area.

- These structural forms result in structures that can be fully stressed since there is no need to consider bending or buckling which results in very efficient use of the materials used.

- These structures may be prefabricated and can be manufactured in the most efficient method.

\section{ANALYSIS AND DESIGN TENSILE STRUCTRURES}

\section{Design considerations}

The design of tensile membrane structures comes with several considerations that need not be made for conventional structures. These include certain load and climate conditions, availability of material and labour, acoustic performance, fire protection, energy use and lights, as well as material maintenance, durability, and inspection.

\section{Tensile membrane structures work}

Beams and columns in these structures can resist axial, shear, and bending stresses. Fabric structures, on the other hand, are so lightweight that gravity does not have any serious effect. Discussing the behaviour of a single cable can therefore help to illustrate certain behavioural properties of a fabric membrane. To understand this behaviour consider the uniformly loaded beam and it's bending moment diagram in Figure 1.

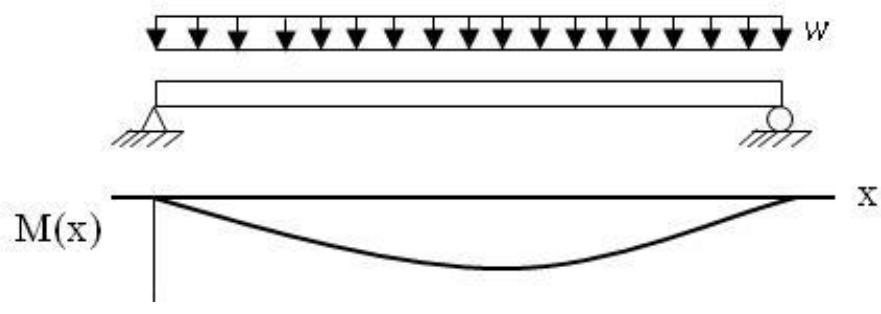

Fig 1 . Uniformly loaded beam and moment diagram

Now consider the uniformly loaded cable and deflected shape in Figure 2, $w$ is the load per unit length, $\mathrm{L}$ is the total length of cable, $\mathrm{h}$ is the maximum vertical deflection at midpoint, and $\mathrm{H}$ and $\mathrm{V}$ are horizontal and vertical reaction 
forces, respectively.

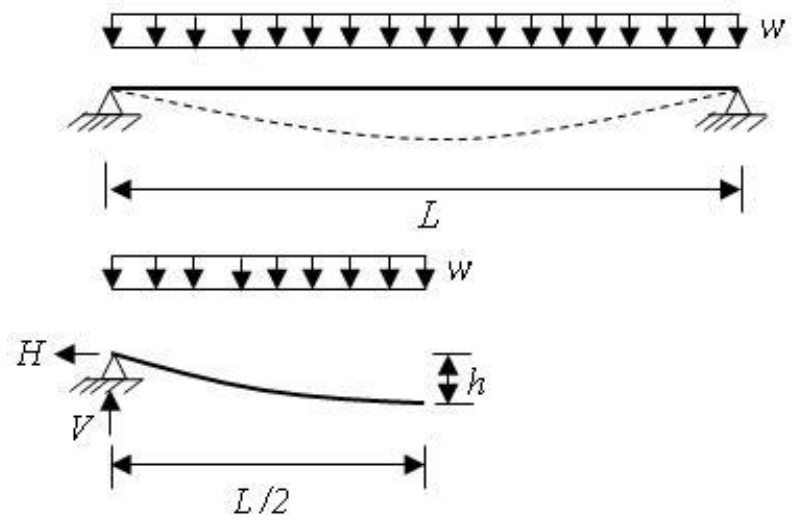

Fig 2. Uniformly loaded cable

Equilibrium in the vertical direction yields:

$$
\mathrm{V}=\frac{\omega \mathrm{L}}{2} \quad
$$

Because cables cannot resist bending, sum of moments about any point will be equal to zero.

$\sum \mathrm{M}_{\text {midpo int }}=0$

$H(h)+\omega\left(\frac{L}{2}\right)\left(\frac{L}{4}\right)-V\left(\frac{L}{2}\right)=0$

$H=\frac{\omega L^{2}}{8 h}$

And the force in the cable is:

$\mathrm{F}=\sqrt{\mathrm{V}^{2}+\mathrm{H}^{2}}$

\section{Tensile membrane design process}

A description of the tensile membrane design process is shown in Figure 3, from the preliminary to the realization of the structure.

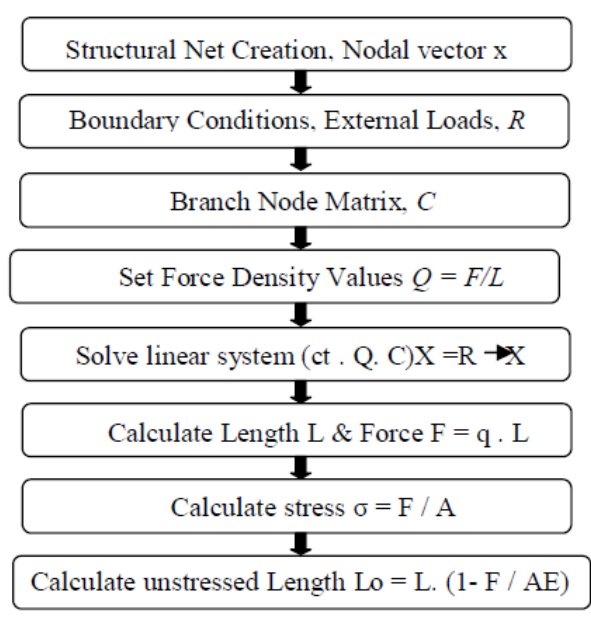

Fig 3. Force - density methods

\section{EXAMPLES OF DESIGN}

Example for three types of tensile membrane designed by using Forten2000 software included all process design Tensile membrane. As shown in Figures below, boundary tensioned membranes type which shown steps of boundaries type.

Figures 4, shown the steps of boundaries with Polar-mesh and Tri-mesh before form finding, the Figure 5 shown the boundaries and shaded after form finding or presented the general view of structure after form finding. The Figure 6 shown the final design which presented the membrane stress $(\sigma 11)$ of form finding.

Shown in the Figure 6, membrane stress $(\sigma 11)$ after form finding for boundary type of tensile membrane variation between $0 \mathrm{~kg} / \mathrm{m}$ and $1348.259 \mathrm{~kg} / \mathrm{m}$. The steps same for another types of tensile membrane design meshing, shaded and stress respectively. Figure 7 shown final step of example Conical shape with middle mast presented second type of membrane design Cable-nets and cable-beams.

As seen in Figure 7, the membrane stress $(\sigma 11)$ of form finding range between $0 \mathrm{~kg} / \mathrm{m}$ and $981.187 \mathrm{~kg} / \mathrm{m}$.

Figure 8 , shown example of pneumatic structures, as seen the membrane stress $(\sigma 11)$ of form finding range between $95.691 \mathrm{~kg} / \mathrm{m}$ and $620.575 \mathrm{~kg} / \mathrm{m}$. The range of stress less than other types because of membrane thin not allowed very high stress. 

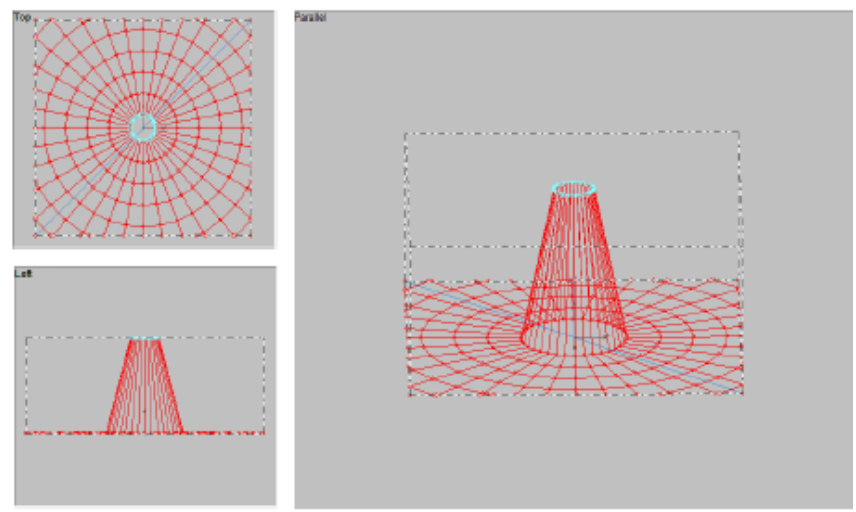

(A)
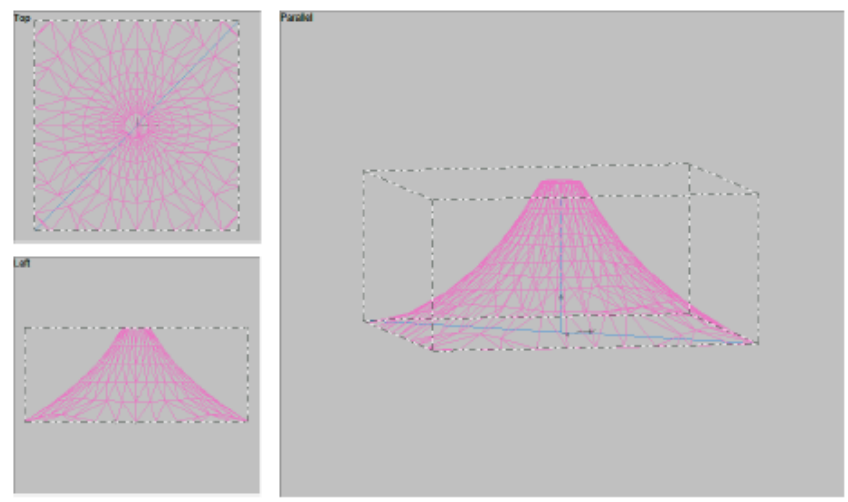

(B)

Fig 4. The Boundaries (A) polar mesh before form finding (B) Tri-mesh before form finding
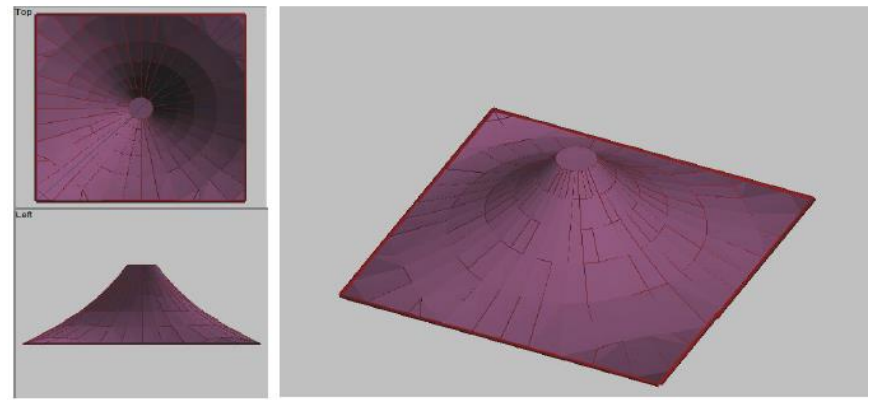

Fig 5. The Boundaries and Shaded after form finding
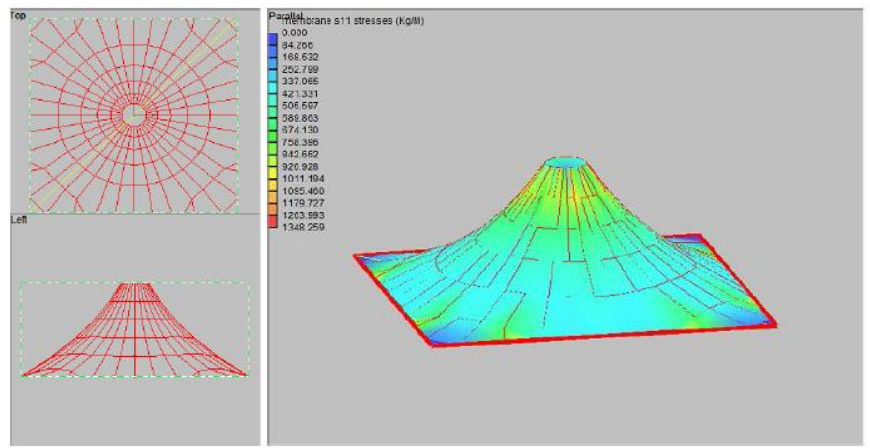

Fig 6. The membrane stress $\left(\sigma_{11}\right)$ of form finding for Boundary tensioned membranes

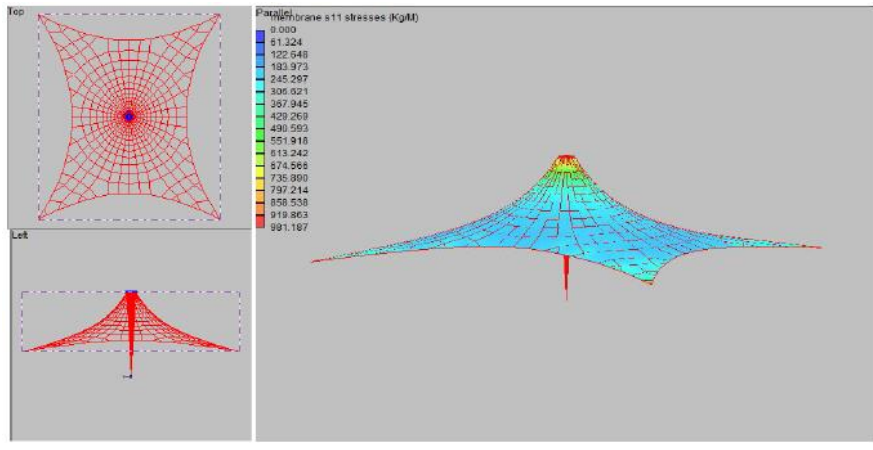

Fig 7. The membrane stress $\left(\sigma_{11}\right)$ of form finding for Cable-nets and cablebeams
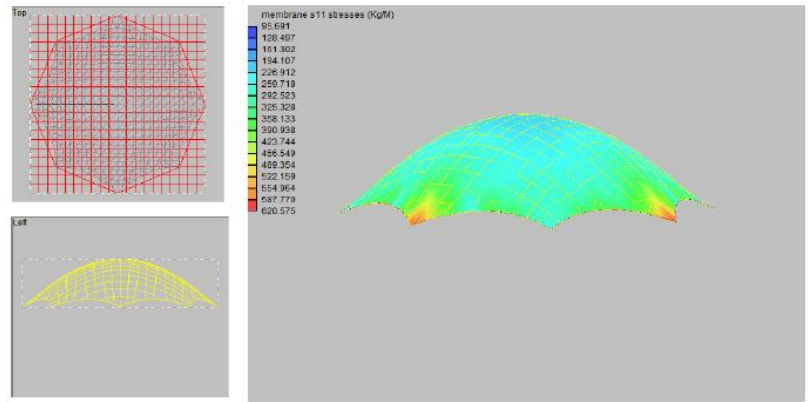

Fig 8 . The membrane stress $\left(\sigma_{11}\right)$ of form finding for pneumatic membrane structures.

\section{CONCLUSION}

Tensile membrane structures represent a new chapter in the history of building structures. Capable of spanning large distances while incurring very little weight on supporting structure, developments in the design of tensile membrane structure can dramatically change the way we conceptualize permanent building construction. Small changes to the dimensions or specifications of a fabric structure usually result in major or complete re-design.

The advent of computer technology changed tensile architecture for ever. The possibilities of accurately calculating form and values for ever more complicated project proposals opened the door to an architectural language.

In the future work the use of "black box" software should be strongly resisted. It is necessary to develop an engineering analysis and design software for further study on tensile membrane structures. The key points in the development of engineering analysis software for tensile membrane structures are that it should not place any limitations on the design process, should have a clear physical analogy, should integrate computer aided geometry design, structural analysis and optimization methods, and most importantly, by fully understood by the engineering. 


\section{REFERENCES}

[1] Bogner F.K., (1968). Analysis of tension structures. Bell Telephone Laboratories, Incorporated Whippany, Report No: AFFDL-TR-68150 ,New Jersey.

[2] Ishii K., (1999). Membrane designs and structures in the world. Shinkenchikusha Co., Ltd., Tokyo.

[3] Zhang J., (2005). Optimization Problems for Design and Maintenance of Forces and Shape of Tension Structures. M.Sc. thesis, Department of Architecture and Architectural Engineering, Kyoto University, Japan.

[4] BAKBAK D., (2011). Architectural Form Design and Structural Analysis of Tensile Structures. M.Sc. thesis, Department of Civil Engineering, Gaziantep University, Turkey.

[5] Lewis W. J., (2003). Tension structures: form and behaviour, Thomas Telford, London.

[6] Kronenburg R., (1996). Portable Architecture. Architectural Press. 